\title{
THE
}

\section{Cost and Utilization of Behavioral Health Medications Associated with Rescission of an Exemption for Prior Authorization for Severe and Persistent Mental Illness in the Vermont Medicaid Program}

\author{
Brian J. Quilliam \\ University of Rhode Island, bquilliam@uri.edu \\ C. Simeone \\ University of Rhode Island \\ Rita M. Marcoux
}

Follow this and additional works at: https://digitalcommons.uri.edu/php_facpubs

Terms of Use

All rights reserved under copyright.

\section{Citation/Publisher Attribution}

Simeone, J. C., Marcoux, R. M., \& Quilliam, B. J. (2010). Cost and Utilization of Behavioral Health Medications Associated With Recission of an Exemption for Prior Authorization for Severe and Persistent Mental Illness in the Vermont Medicaid Program. Journal of Managed Care Pharmacy, 16(5), 317-328. doi: 10.18553/jmcp.2010.16.5.317

Available at: http://dx.doi.org/10.18553/jmcp.2010.16.5.317

This Article is brought to you for free and open access by the Pharmacy Practice at DigitalCommons@URI. It has been accepted for inclusion in Pharmacy Practice Faculty Publications by an authorized administrator of DigitalCommons@URI. For more information, please contact digitalcommons-group@uri.edu. 


\title{
Cost and Utilization of Behavioral Health Medications Associated with Rescission of an Exemption for Prior Authorization for Severe and Persistent Mental IIIness in the Vermont Medicaid Program
}

\author{
Jason C. Simeone, PhD; Rita M. Marcoux, MBA, RPh; and Brian J. Quilliam, PhD, RPh
}

\begin{abstract}
BACKGROUND: In recent years, many state Medicaid programs have implemented preferred drug lists (PDL) to control pharmaceutical costs by generating supplemental rebate revenues and directing providers to the most cost-effective treatments. Two states, Michigan and Vermont, sought approval from the Centers for Medicare \& Medicaid Services for supplemental rebates for their Medicaid fee-for-service programs in 2002. Behavioral health medications were largely excluded from PDLs and other managed care initiatives implemented by state Medicaid programs because of significant opposition to any impact on this "vulnerable" population. In November 2001, the Vermont Medicaid program implemented the Vermont Health Access Pharmacy Benefit Management Program, a PDL designed to promote cost-effective use of medications. Despite the potential cost savings resulting from implementation of a PDL, behavioral health providers and advocates in the state of Vermont opposed the implementation of the managed care initiative for beneficiaries with severe mental illness, and after January of 2002, Vermont's program was changed to exempt beneficiaries meeting the "severe and persistent mental illness" (SPMI) criteria from prior authorization (PA) for behavioral health medications not on the Medicaid PDL. The SPMI exemption was phased out by June 30, 2006.
\end{abstract}

OBJECTIVES: To determine the effects of the rescission of the PA exemption on utilization and costs of 3 classes of behavioral health medications (antidepressants, antipsychotics, and anxiolytics/sedatives). Secondary analyses were conducted to assess the association between rescission of the PA exemption and 2 quality measures that might be associated with pharmacy management policy: (a) behavioral health hospitalizations and (b) high-dose prescribing of antipsychotics, defined as dosing that exceeded the manufacturer-recommended maximum dose by $25 \%$.

METHODS: This was a retrospective analysis of pharmacy claims for beneficiaries of the Office of Vermont Health Access Medicaid Program for dates of service from July 1, 2005, through December 31, 2007. The 12-month PA exemption period for 3 categories of drugs (antidepressants, antipsychotics, and anxiolytics/sedatives) was July 1, 2005, through June 30, 2006; and the post-PA exemption period was the 12 months from January 1, 2007, through December 31, 2007, following rescission of the SPMI exemption. Costs in this analysis were defined as the amount paid by Medicaid, excluding federal drug rebates paid by drug manufacturers and supplemental rebates associated with the PDL program. Costs were adjusted for inflation using the Consumer Price Index for medical costs. Frequencies were used to identify trends between medication classes and time periods. Medical claims from the 2 time periods were used to assess inpatient hospitalization trends. Descriptive statistics, Pearson chi-square tests (for categorical data), and t-tests (for continuous data) were used to assess the 2 study cohorts.

RESULTS: $17.8 \%(n=22,130)$ of 124,169 eligible beneficiaries in the PA exemption period had 1 or more pharmacy claims in the 3 classes of medications exempt from PA versus $19.2 \%(n=23,717)$ of 123,499 eligible beneficiaries in the post-PA exemption period. Utilization of behavioral medications per member per month (PMPM) increased by $14.3 \%$ from 0.14 claims PMPM in the PA exemption period to 0.16 claims PMPM in the post-PA exemption period, similar to the $14.1 \%$ increase in the utilization of nonbehavioral medications (from 0.64 to 0.73 claims PMPM). Utilization changed little between the PA exemption period and the post-PA exemption period for the 3 individual classes of behavioral health drugs, 0.08 claims PMPM versus 0.09 claims PMPM for antidepressants and 0.03 for both study periods for both antipsychotics and anxiolytics/sedative hypnotics. PMPM costs for the 3 drug classes exempt from PA increased by $2.1 \%$ from $\$ 12.76$ to $\$ 13.03$, compared with a $12.2 \%$ increase from $\$ 42.58$ PMPM to \$47.79 PMPM for nonbehavioral health medications. The small $2.1 \%$ increase in PMPM costs for the 3 formerly PA-exempt drug classes was attributable in part to a $12.9 \%$ reduction in average cost per pharmacy claim, from $\$ 94.05$ to $\$ 81.92$, including a $24.8 \%$ reduction in the average cost per antidepressant claim, from $\$ 65.59$ to $\$ 49.33$. For the subgroup of beneficiaries taking atypical antipsychotic medications, the percentage with high-dose prescriptions decreased from $3.1 \%$ to $2.2 \%$. Mental health inpatient hospitalizations also decreased from $0.6 \%$ of beneficiaries in the PA exemption period to $0.4 \%$ in the post-PA exemption period.

CONCLUSIONS: In a Medicaid population excluding Medicare dual-eligible beneficiaries, the rescission of a PA exemption for 3 major classes of behavioral health medications in a PDL was not associated with decreased utilization of formerly PA-exempt behavioral health medications. The increase in PMPM spending for the formerly PA-exempt behavioral health medications was small compared with the increase in PMPM cost for nonbehavioral health medications, and there were fewer beneficiaries with hospitalization for mental health reasons in the period after rescission of the PA exemption.

\section{J Manag Care Pharm. 2010;16(5):317-28}

Copyright $\odot$ 2010, Academy of Managed Care Pharmacy. All rights reserved.

\section{What is already known about this subject}

- Most states implemented Medicaid cost containment measures between 2001 and 2005 to control rising pharmaceutical costs; by 2009, 46 states had implemented a prior authorization (PA) program, and 45 states had implemented a preferred drug list (PDL).

- Medicaid currently pays for greater than 50\% of all publicly funded behavioral health care and greater than $25 \%$ of all behavioral health care nationwide. Previous studies have shown that managed care initiatives reduce expenditures but can have variable effects on health care utilization. 


\section{Cost and Utilization of Behavioral Health Medications Associated with Rescission of an Exemption for Prior Authorization for Severe and Persistent Mental Illness in the Vermont Medicaid Program}

\section{What this study adds}

- After rescission of a PA exemption and implementation of a behavioral health PA requirement in the Vermont Medicaid program, per member per month pharmaceutical costs for behavioral health medications increased by $2.1 \%$ compared with a $12.2 \%$ increase for all nonbehavioral health medications, and utilization of the formerly PA-exempt behavioral health medications did not decrease.

- Preliminary results indicate that implementation of a PDL and corresponding PA program for a mental health subgroup of the Medicaid population were not associated with an increase in inpatient mental health hospitalizations, and use of high-dose antipsychotics (meeting the threshold for PA) decreased from $3.1 \%$ to $2.2 \%$ of beneficiaries.

I mplementation of the Medicare Part D drug benefit on January 1, 2006, shifted about one-half of Medicaid spending (for dual-eligible beneficiaries) to the Medicare program, but states continued to seek control of rising pharmaceutical costs using tools such as preferred drug lists (PDLs), prior authorization (PA), and supplemental rebate programs that were initiated between 2001 and 2005. ${ }^{1}$ By 2009, 45 state Medicaid programs had a PDL, and 46 states had PA requirements for pharmaceuticals. Increases in Medicaid spending per beneficiary declined from $14.0 \%$ in $2000-2002$ to $0.7 \%$ in $2005-2007$, after adjustment for the shift of costs to Medicare for dual-eligible beneficiaries. ${ }^{2}$ Prescription drug trends are driven by a number of factors including price increases, utilization, mix, the introduction of new products, pharmaceutical advertising, and the increasing number of biotechnology products used to treat chronic conditions. ${ }^{3}$ Fiscal constraints are requiring Medicaid officials to seek innovative approaches to delivering quality health care to an increasing number of individuals requiring care for complex and chronic health conditions.

According to the Centers for Medicare \& Medicaid Services (CMS), 33.4 million beneficiaries or approximately $71 \%$ of the national Medicaid population were enrolled in a managed care program by 2008. ${ }^{4}$ Every state except Alaska and Wyoming has all, or a portion, of its Medicaid population enrolled in some form of managed care. ${ }^{1}$ Managed Medicaid organizations generate rebates that do not benefit from the best price mandates of the Omnibus Budget Reconciliation Act (OBRA) rebate program administered by CMS. While states do share in OBRA rebates with the federal government, a few states challenged CMS to allow them to work with pharmaceutical manufacturers to increase their rebate revenue by entering into supplemental rebate agreements based on the implementation of PDLs in their states. ${ }^{1,5}$ Manufacturers agreed to pay additional rebates for preferred placement on the Medicaid PDLs. Although physicians are permitted to prescribe all medications, "preferred" medications do not require PA when the pharmacy claim is submitted.

In the late 1990's, behavioral health medications were largely excluded from PDLs and managed care initiatives implemented by state Medicaid fee-for-service programs out of concern for the "vulnerability" of the beneficiaries taking these medications. ${ }^{6}$ This exclusion from managed care and care management initiatives occurred at a time when spending on behavioral health medications represented approximately $20 \%$ of all Medicaid drug expenditures. ${ }^{7}$ Increased utilization is likely a result of several factors; newer medications may have fewer side effects, and there has been a decrease in the stigmatization of individuals taking behavioral medications. In addition, antidepressants, antipsychotics, and anxiolytics are increasingly being prescribed for off-label uses. ${ }^{8}$ American pharmaceutical manufacturers are developing at least 300 new medications designed to treat the nearly 60 million Americans suffering from behavioral disorders. ${ }^{9}$ Although the development of so many new medications to treat behavioral disorders is promising, states must still ensure that behavioral health programs are meeting the needs of their beneficiaries in a fiscally responsible manner.

The State of Vermont's Medicaid program is managed by the Office of Vermont Health Access (OVHA), and OVHA programs cover approximately 175,000 beneficiaries. In early 2000, government officials in Vermont were under constant pressure to control increasing drug expenditures without reducing services. ${ }^{10}$ In 2002, the General Assembly adopted legislation authorizing a prescription drug cost containment program that included the implementation of a PDL and a PA program for nonpreferred drugs. ${ }^{11-12}$ A number of constituent groups in the mental health advocacy community, including caregivers and physicians, supported an exemption from PA for behavioral health medications in the PDL. ${ }^{13}$ In response to their concerns, the Vermont legislature exempted beneficiaries identified as having "severe and persistent mental illness" (SPMI) from PA for any medication being used to treat their behavioral health illness regardless of the positioning of the medication on the PDL. ${ }^{14}$ The SPMI designation was defined in 2002 by the following criteria: ${ }^{14}$

- Patient diagnosed with schizophrenia or bipolar disorder.

- Patient diagnosed with an International Classification of Diseases, Ninth Revision, Clinical Modification (ICD-9-CM) diagnosis code for mental health or substance abuse (including major depression, 290.00-319.00) and has or has had a history of impairment due to the mental illness that affects his/her ability to function such that the patient is suicidal, has no friends, neglects family, is unable to work or keep a job, is withdrawn to home or room, stays in bed all day, becomes violent, or has even lesser degrees of functioning (Global Assessment of Functioning Scale score of 50 or less). 


\section{Cost and Utilization of Behavioral Health Medications Associated with Rescission of an Exemption for Prior Authorization for Severe and Persistent Mental Illness in the Vermont Medicaid Program}

- Patient is a past or current user of traditional or atypical antipsychotic medication.

- Patient has received chronic therapy with any antidepressant medication (received at least 300 days supply of medication during a 365 day period).

- Patient has received chronic therapy with any central nervous system stimulant medication (received at least 240 days supply of medication during a 365 day period).

- Presence of a Community Rehabilitation and Treatment (CRT) code in eligibility file.

- Patient less than 18 years of age.

SPMI exemption was determined on each pharmacy claim; therefore an overall marker of the SPMI exemption was not a part of a beneficiary's eligibility file, and exemption was determined each time the beneficiary presented a new prescription for a behavioral health medication. Furthermore, the policy stipulated that a beneficiary found to be exempt for any reason other than age would remain exempt as long as he or she continued to meet at least 1 of the SPMI exemption criteria. ${ }^{14}$ This inclusive exemption policy gave prescribers continued flexibility in managing the care of these SPMI beneficiaries while allowing the OVHA the ability to implement the new PDL and PA policy to ensure fiscal and clinical responsibility of the overall program. A new initiative was added as part of the PA policy that monitored the use of highdose prescribing of behavioral health medications to ensure that patients did not continue to receive high-dose therapy that offered limited or no clinical benefit. The program and its PDL were authorized by the state legislature in 2002 for implementation in the state fiscal year ending June 30, 2002. ${ }^{14}$ Both current and historical OVHA PDLs are available online on the OVHA website (http://ovha.vermont.gov/for-providers/ preferred-drug-list-clinical-criteria). The SPMI exemption to the PDL and PA program was scheduled to end July 1, 2004, but was extended through June 30, 2006. In response to concerns from the health care community and caregivers, the OVHA permitted beneficiaries using nonpreferred medications prior to the exemption rescission to be "grandfathered" to prevent "destabilization" of therapy. However, lapses in drug therapy of 4 months or longer resulted in the application of the PDL for these beneficiaries. ${ }^{14}$

The utilization and cost of these behavioral health medications continued to escalate and remained in the top therapeutic classes by expenditure in the state Medicaid program through 2005. The 2006 Budget Act passed by the Vermont legislature had provisions to allow the inclusion of behavioral health drugs on the PDL. ${ }^{14}$ In 2006, the OVHA revised its PDL and PA program to include the previously exempt behavioral health classes of medications, and SPMI patients were then subject to the PDL program requirements..$^{14}$ The phase-out of the PA exemption was not implemented in a "hard edit" in the pharmacy claims processing system until June 2006 because of the major changes that took place with eligibility associated with implementation of the Medicare Part D benefit beginning in January 2006.

We conducted a retrospective study of PA exemption and post-PA exemption cohorts to assess the association of Vermont's implementation of a PDL and PA program for behavioral health medications with health care utilization and costs. We evaluated (a) behavioral health medication utilization and drug costs in 3 of the major drug classes, and (b) 2 measures that might capture some of the possible adverse consequences of drug use restrictions: use of high-dose antipsychotic agents and mental health hospitalizations before and after the rescission of the SPMI exemption.

\section{Methods}

We conducted a nonconcurrent retrospective cohort study, evaluating 2 time periods in relation to OVHA's rescission of the SPMI exemption. The first time period for this analysis, July 1, 2005 to June 30, 2006, represented the final 12-month period during which beneficiaries who were designated as SPMI were exempt from PDL and PA requirements for behavioral health medications, hereafter referred to as the PA exemption period. We identified a second 12-month period during which the PDL and PA programs were fully implemented from January 1, 2007 through December 31, 2007, as the post-PA exemption period. Our selection of these time periods allowed for a 6-month wash-out period after rescission of the SPMI exemption. For each of these time periods, we included all beneficiaries with continuous enrollment during the interval. From these eligible populations, we then excluded: (a) persons eligible for Medicare Part D including dual eligibles (because Medicare became the primary payer for pharmaceuticals beginning in January 2006, and the OVHA as secondary payer did not apply the PDL and PA program to these claims); (b) beneficiaries who qualified for pharmaceutical aid from state programs other than Medicaid; and (c) beneficiaries being treated for hemophilia and Hunter's syndrome (because high costs for associated pharmaceutical agents would skew the cost analyses). After the exclusion of beneficiaries, 124,169 Medicaid beneficiaries qualified during the PA-exemption period (Figure 1), and 123,449 beneficiaries qualified for inclusion in the post-PA exemption period (Figure 2).

Simple descriptive statistics were used to describe the characteristics of the populations in both study periods. Descriptive statistics included means and standard deviations (for continuous covariates) and frequencies (for categorical variables of interest). We compared the 2 time periods for differences in demographic characteristics including age, gender, and race/ ethnicity using data collected by OVHA and contained in the Vermont Medicaid eligibility files. 


\section{FIGURE 1 Selection of Beneficiaries for PA Exemption Cohort}

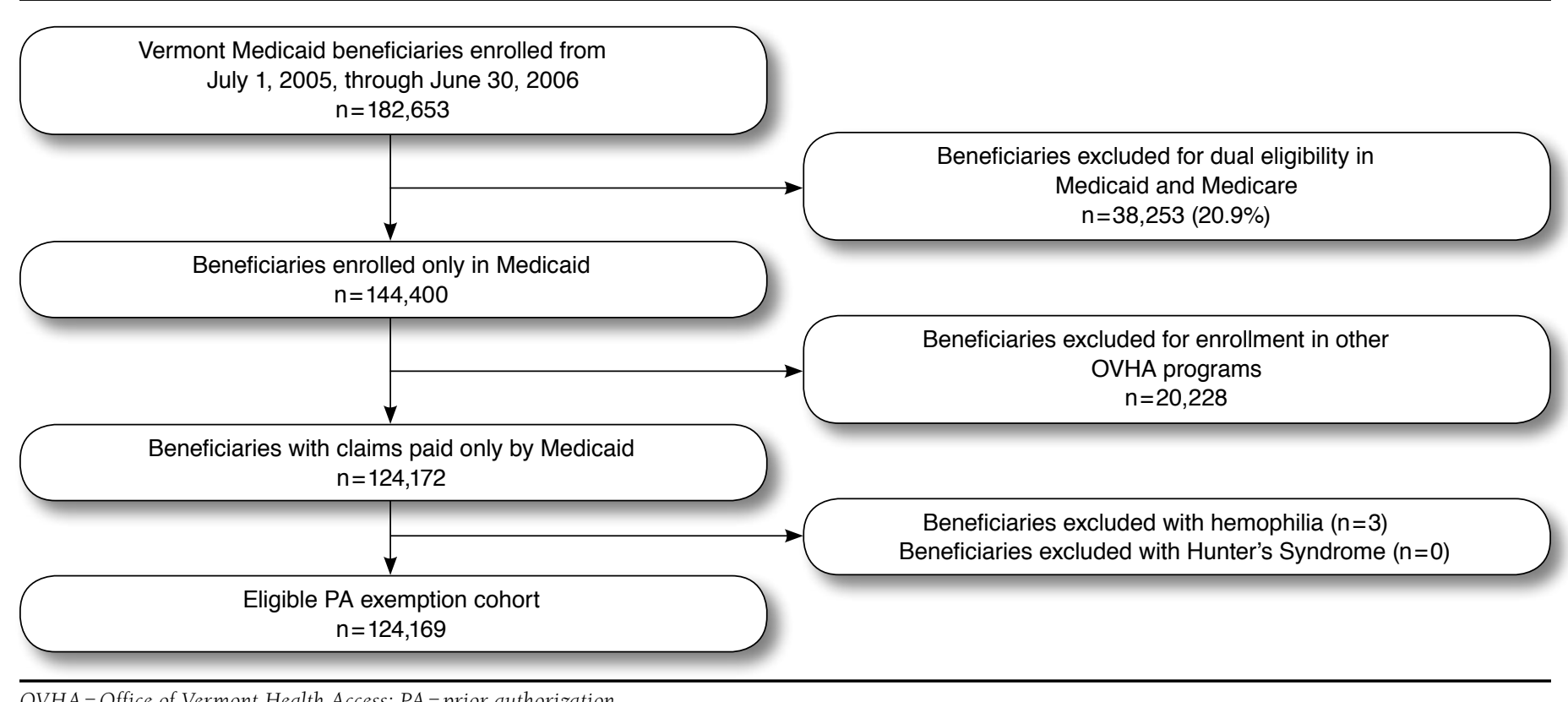

OVHA = Office of Vermont Health Access; PA = prior authorization.

\section{Behavioral Medication Utilization and Cost Analyses}

The next phase of these analyses entailed estimating the prevalence of behavioral medication use and the associated costs to the Medicaid program. For our analyses, we focused on 3 distinct classes of medications that were included in the SPMI exemption: antidepressants, antipsychotics, and anxiolytics/ sedative hypnotics. The OVHA uses the First DataBank (First DataBank, San Francisco, CA) Specific Therapeutic Class (STC) codes to identify drug classes. To identify medications of interest, we used STC codes to identify claims among eligible beneficiaries for antidepressants (e.g., duloxetine, sertraline, and amitriptyline), antipsychotics (e.g., aripiprazole, haloperidol) and anxiolytics/sedative hypnotics (i.e., anti-anxiety medications such as alprazolam; and barbiturate and nonbarbiturate sedative-hypnotics such as zolpidem). After preliminary identification of pharmacy claims using these STC codes, we also completed a text-string search to verify the medications listed in each class identified during the preliminary classification. We estimated utilization rates for overall behavioral health medication at the beneficiary level where the denominator included the total number of eligible beneficiaries within each cohort and the numerator included the total number of beneficiaries utilizing at least 1 behavioral health medication (antidepressant, antipsychotic, or anxiolytic/sedative hypnotic). Similar calculations were completed for each individual drug class, including antidepressants, antipsychotics, and anxiolytics/sedative hypnotics. Differences in the use of behavioral health medications overall and by individual class were compared between the 2 cohorts by frequencies and Pearson chi-square testing.

Because part of the PDL initiative focused on excessive dosing of antipsychotics, we further evaluated differences in the prescription of antipsychotic medications above the daily dose requiring PA (according to OVHA) across the 2 study periods. Utilizing National Drug Codes (NDC), we identified the strength of the antipsychotic medication dispensed and calculated the average daily dose using the number of units dispensed and days supply reported in pharmacy claims (average daily dose $=$ [strength $\mathrm{X}$ units] $\div$ days supply). We then dichotomized this dose as above or below 125\% of the manufacturer's maximum daily dose, as specified in OVHA "dosage guidelines for PA" (aripiprazole $\geq 40$ milligrams [mg]; clozapine $\geq 1,125$ $\mathrm{mg}$; olanzapine $\geq 50 \mathrm{mg}$; quietapine $\geq 1,000 \mathrm{mg}$; risperidone $\geq 10 \mathrm{mg}$; and ziprasidone $\geq 200 \mathrm{mg})^{14}$ and compared this quantity between the 2 cohorts using Pearson chi-square analysis.

To compare costs for behavioral health medications in each of the cohorts, we analyzed costs paid by the Vermont Medicaid program (not including manufacturer rebates from federal payments and supplemental rebates) after adjusting for inflation utilizing methods developed by the Bureau of Labor Statistics. ${ }^{15}$ All costs were adjusted for inflation according to the December 2007 Consumer Price Index (CPI) for medical costs in the Boston-Brockton-Nashua area (December, 2007 CPI=489.8), which was the closest available geographical area to Vermont. 


\section{Cost and Utilization of Behavioral Health Medications Associated with Rescission of an Exemption for Prior Authorization for Severe and Persistent Mental IIIness in the Vermont Medicaid Program}

\section{FIGURE 2 Selection of Beneficiaries for Post-PA Exemption Cohort}

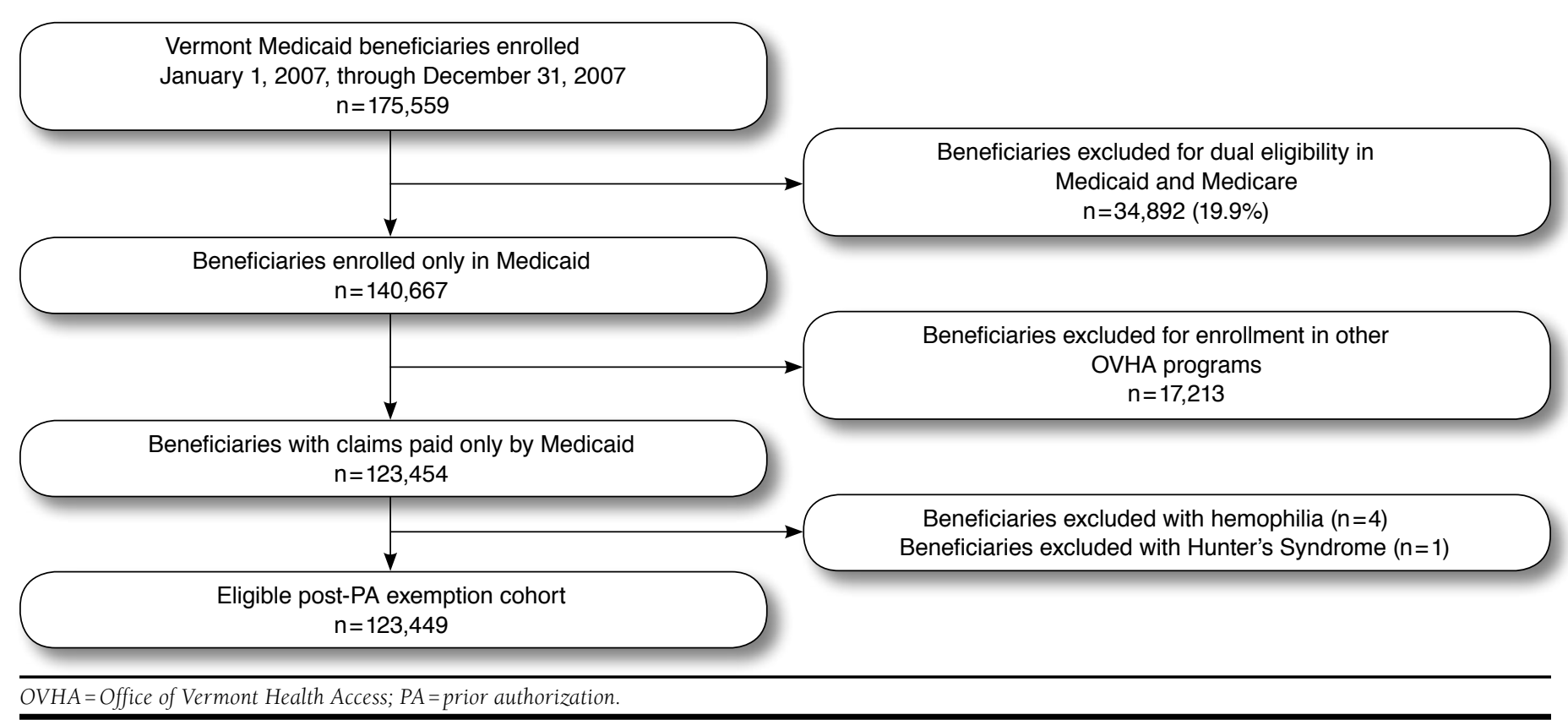

For each month during the study period, we identified the CPI for medical care costs in the Boston-Brockton-Nashua Area (e.g., CPI $=456.7$ for June 2006). We then determined the percent inflation by dividing the CPI for December, 2007 by the CPI for each month during the study period. Costs within each month were then multiplied by this factor to adjust the costs for inflation. Within each cohort, we calculated per member per month (PMPM) costs for all pharmaceuticals (including behavioral health medications), for nonbehavioral health medications, for behavioral health medications overall, and for each of the 3 classes of behavioral health medications. We then compared costs across the 2 cohorts utilizing t-tests.

\section{Behavioral Health Hospitalizations}

Finally, as shifts in drug utilization patterns may affect behavioral health hospitalizations, we assessed rates of hospitalization between the 2 cohorts. We identified all hospitalizations for each study period where a mental health disorder (bipolar disorder, depression, schizophrenia, personality disorders, anxiety disorders, and other mental health disorders such as delusional disorders and pervasive developmental disorders) was listed as the principal diagnosis on the facility claim (Table 1). Inpatient hospitalizations were identified using a unique claim type code present in the Vermont Medicaid database. The claim type code for inpatient claims includes hospitalizations at general hospitals, freestanding psychiatric hospitals, and state mental health hospitals. We then compared the

\section{TABLE 1 Hospitalization and Drug Class Codes}

\begin{tabular}{|c|c|}
\hline $\begin{array}{l}\text { Primary } \\
\text { Hospitalization } \\
\text { Diagnosis }\end{array}$ & ICD-9-CM Codes \\
\hline Depression & $296.2,296.3,298.0,300.4,309.0,309.1$ \\
\hline Schizophrenia & $295.0-295.9$ \\
\hline Bipolar disorder & $296.0,296.1,296.4-296.8$ \\
\hline Personality disorder & 301.xx except 301.21 \\
\hline Anxiety disorder & $\begin{array}{l}300.0-300.02,300.11,300.21-300.23,300.3, \\
300.7,300.81,300.82,309.81\end{array}$ \\
\hline $\begin{array}{l}\text { Other mental health } \\
\text { disorders }\end{array}$ & $\begin{array}{l}297.0-297.9,298.2-298.4,298.9,299.0-299.9 \\
300.10,300.5,300.6,300.8,302.0-302.9,306.0- \\
307.9,308.0-308.9,309.22,309.23,309.29 \\
309.82,309.83,310.0-310.9,312.0-316.9\end{array}$ \\
\hline Drug Classes & Drug Class Codes ${ }^{a}$ \\
\hline Antipsychotics & $\begin{array}{l}\text { H2G, H2L, H7O, H7P, H7R, H7S, H7T, H7U, H7X, } \\
\text { H7Z }\end{array}$ \\
\hline Antidepressants & $\begin{array}{l}\text { H2J, H2K, H2S, H2U, H2W, H2X, H7B, H7C, } \\
\text { H7D, H7E, H7J }\end{array}$ \\
\hline $\begin{array}{l}\text { Anxiolytics/sedative } \\
\text { hypnotics }\end{array}$ & $\mathrm{H} 2 \mathrm{D}, \mathrm{H} 2 \mathrm{E}, \mathrm{H} 2 \mathrm{~F}$ \\
\hline \multicolumn{2}{|c|}{$\begin{array}{l}\text { aFirst DataBank Specific Therapeutic Class (STC) codes (First DataBank, San } \\
\text { Francisco, CA). } \\
\text { ICD-9-CM = International Classification of Diseases, Ninth Revision, Clinical } \\
\text { Modification. }\end{array}$} \\
\hline
\end{tabular}

proportions of inpatient hospitalizations from each study period using Pearson chi-square testing.

All statistical tests were performed using an a priori 
Cost and Utilization of Behavioral Health Medications Associated with Rescission of an Exemption for Prior Authorization for Severe and Persistent Mental Illness in the Vermont Medicaid Program

\section{TABLE 2 Demographic Characteristics of All Vermont Medicaid Beneficiaries} Eligible for Study Inclusion Stratified by Study Period ${ }^{\mathrm{a}}$

\begin{tabular}{|c|c|c|c|}
\hline Variable & $\begin{array}{c}\text { PA Exemption Cohort } \\
n=124,169^{\mathrm{b}}\end{array}$ & $\begin{array}{l}\text { Post-PA Exemption Cohort } \\
n=123,449^{c}\end{array}$ & $P$ Valued \\
\hline \multicolumn{4}{|l|}{ Age } \\
\hline Mean $[\mathrm{SD}]$ and t-test $P$ value & $20.4[16.4]$ & $21.2[17.0]$ & $<0.001$ \\
\hline \multicolumn{4}{|l|}{ Age ranges in years } \\
\hline \multicolumn{4}{|c|}{$\%$ (n) Pearson chi-square $P$ value } \\
\hline Younger than 18 & $54.9 \% \quad(68,095)$ & $53.0 \% \quad(65,420)$ & \multirow{4}{*}{$<0.001$} \\
\hline $18-34$ & $24.6 \% \quad(30,597)$ & $24.9 \% \quad(30,691)$ & \\
\hline $35-64$ & $20.2 \% \quad(25,058)$ & $21.8 \% \quad(26,853)$ & \\
\hline 65 or older & $0.3 \% \quad(381)$ & $0.4 \% \quad(448)$ & \\
\hline \multicolumn{4}{|l|}{ Gender } \\
\hline \multicolumn{4}{|c|}{$\%$ (n) Pearson chi-square $P$ value } \\
\hline Female & $53.8 \% \quad(66,726)$ & $53.8 \% \quad(66,341)$ & \multirow{2}{*}{0.995} \\
\hline Male & $46.2 \% \quad(57,405)$ & $46.2 \% \quad(57,071)$ & \\
\hline \multicolumn{4}{|l|}{ Race } \\
\hline \multicolumn{4}{|c|}{$\%$ (n) Pearson chi-square $P$ value } \\
\hline Black & $1.2 \% \quad(1,532)$ & $1.3 \% \quad(1,577)$ & \multirow{4}{*}{0.067} \\
\hline White & $55.6 \% \quad(68,993)$ & $55.4 \% \quad(68,316)$ & \\
\hline Other & $0.8 \% \quad(997)$ & $0.9 \% \quad(1,109)$ & \\
\hline Not known/not reported & $42.4 \% \quad(52,609)$ & $42.5 \% \quad(52,410)$ & \\
\hline \multicolumn{4}{|c|}{$\begin{array}{l}\text { aPercentages may not total 100\% due to rounding. The PA exemption period was the } 12 \text { mo } \\
\text { was the } 12 \text { months between January } 1,2007 \text {, and December } 31,2007 \text {. } \\
\text { b38 beneficiaries were missing demographic information in the PA exemption cohort. } \\
\text { '37 beneficiaries were missing demographic information in the post-PA exemption cohort. } \\
{ }^{d} T \text {-test for the comparison of mean age and Pearson chi-square for the other characteristics. } \\
P A=\text { prior authorization; } S D=\text { standard deviation. }\end{array}$} \\
\hline
\end{tabular}

\section{TABLE 3 Users of Behavioral Health Medications}

\begin{tabular}{|c|c|c|c|c|c|c|}
\hline & $\begin{array}{c}\text { PA Exemption } \\
\text { Cohort }^{\mathrm{a}} \\
\mathrm{n}=124,169\end{array}$ & $\begin{array}{c}\text { Post-PA Exemption } \\
\text { Cohort }^{\mathrm{b}} \\
\mathrm{n}=123,449\end{array}$ & $\begin{array}{l}\text { Absolute } \\
\text { Change }\end{array}$ & $\begin{array}{c}\text { Percent } \\
\text { Change (\%) }\end{array}$ & $\begin{array}{l}\text { Pearson } \\
\text { Chi-Square }\end{array}$ & $P$ Value \\
\hline & \multicolumn{2}{|c|}{$\%$ utilizing beneficiaries (n) } & & & & \\
\hline Antidepressants & $14.4 \% \quad(17,872)$ & $15.4 \% \quad(18,968)$ & 1.0 & 6.9 & 46.16 & $<0.001$ \\
\hline SSRI & $10.2 \% \quad(12,694)$ & $11.1 \% \quad(13,697)$ & 0.9 & 8.8 & \multirow{3}{*}{53.09} & \multirow{3}{*}{$<0.001$} \\
\hline TCA & $1.3 \% \quad(1,588)$ & $1.3 \% \quad(1,580)$ & 0.0 & 0.0 & & \\
\hline Otherc & $2.9 \% \quad(3,590)$ & $3.0 \% \quad(3,691)$ & 0.1 & 3.4 & & \\
\hline Antipsychotics & $3.6 \% \quad(4,487)$ & $3.8 \% \quad(4,724)$ & 0.2 & 5.6 & 7.85 & 0.005 \\
\hline Typical & $(678)$ & $(760)$ & 0.1 & 20.0 & \multirow{2}{*}{9.51} & \multirow{2}{*}{0.009} \\
\hline Atypical & $3.1 \% \quad(3,809)$ & $3.2 \% \quad(3,964)$ & 0.1 & 3.2 & & \\
\hline Anxiolytics/sedatives & $6.4 \% \quad(7,956)$ & $7.5 \% \quad(9,240)$ & 1.1 & 17.2 & 111.21 & $<0.001$ \\
\hline Benzodiazepine & $5.1 \% \quad(6,366)$ & $6.0 \% \quad(7,407)$ & 0.9 & 17.6 & \multirow{3}{*}{121.77} & \multirow{3}{*}{$<0.001$} \\
\hline Sleep aid & $1.2 \% \quad(1,462)$ & $1.4 \% \quad(1,736)$ & 0.2 & 16.7 & & \\
\hline Barbiturate & $(128)$ & $0.1 \% \quad(97)$ & 0.0 & 0.0 & & \\
\hline Any behavioral health medication ${ }^{\mathrm{d}}$ & $17.8 \% \quad(22,130)$ & $19.2 \% \quad(23,717)$ & 1.4 & 7.9 & 79.22 & $<0.001$ \\
\hline $\begin{array}{l}\text { aThe PA exemption period was the } 12 \text { mo } \\
{ }^{b} \text { The post-PA exemption period was the } 1 \\
\text { 'Other antidepressants include MAOIs, N } \\
{ }^{d} \text { Beneficiaries in this row were counted or } \\
\text { MAOI = monoamine oxidase inhibitor; NI } \\
\text { inhibitor; SSRI = selective serotonin reupto }\end{array}$ & $\begin{array}{l}\text { S between July } 1,20 \\
\text { nonths between Janu } \\
\text { RIs, SNRIs, and alph } \\
\text { if they had at least } \\
\text { I= norepinephrine ar } \\
\text { inhibitor; TCA = tric }\end{array}$ & $\begin{array}{l}\text { and June 30, } 2006 . \\
\text {, 2007, and December } 3 \\
\text { receptor antagonist antid } \\
\text { armacy claim for antidep } \\
\text { pamine reuptake inhibit } \\
\text { antidepressant. }\end{array}$ & $\begin{array}{l}007 . \\
\text { ssants. } \\
\text { ants, antipsy } \\
A=\text { prior au }\end{array}$ & $\begin{array}{l}\text { CS, or anxiolytic } \\
\text { zation; SNRI =s }\end{array}$ & $\begin{array}{l}\text { datives. } \\
\text { onin-norepinep }\end{array}$ & reuptake \\
\hline
\end{tabular}


Cost and Utilization of Behavioral Health Medications Associated with Rescission of an Exemption for Prior Authorization for Severe and Persistent Mental Illness in the Vermont Medicaid Program

TABLE 4 Beneficiaries Exceeding OVHA Atypical Antipsychotic Daily Dose Limitations ${ }^{a}$

\begin{tabular}{|c|c|c|c|c|c|c|c|}
\hline \multirow[b]{2}{*}{ Medication } & \multirow[b]{2}{*}{$\begin{array}{c}\text { Daily Dose } \\
\text { Requiring PA }\end{array}$} & \multicolumn{2}{|c|}{ PA Exemption Period ${ }^{b}$} & \multicolumn{2}{|c|}{ Post-PA Exemption Period ${ }^{c}$} & \multirow[b]{2}{*}{$\begin{array}{c}\text { Pearson } \\
\text { Chi-Square }\end{array}$} & \multirow[b]{2}{*}{$P$ Value } \\
\hline & & Sample Size & $\begin{array}{c}\%(\mathrm{n}) \\
\text { Exceeding Dose }\end{array}$ & Sample Size & $\begin{array}{c}\%(\mathrm{n}) \\
\text { Exceeding Dose }\end{array}$ & & \\
\hline $\begin{array}{l}\text { All atypical antipsy- } \\
\text { chotics combined }^{d}\end{array}$ & & 4,374 & $3.1 \%(134)$ & 4,586 & $2.2 \%(101)$ & 6.50 & 0.011 \\
\hline Aripiprazole & $\geq 40 \mathrm{mg}$ & 884 & $5.4 \% \quad(48)$ & 880 & $3.4 \% \quad(30)$ & 4.26 & 0.039 \\
\hline Clozapine & $\geq 1,125 \mathrm{mg}$ & 84 & $8.3 \% \quad(7)$ & 91 & $0.0 \% \quad(0)$ & 7.90 & 0.005 \\
\hline Olanzapine & $\geq 50 \mathrm{mg}$ & 385 & $1.0 \% \quad$ (4) & 325 & $1.2 \%$ & 0.06 & 0.809 \\
\hline Quetiapine & $\geq 1,000 \mathrm{mg}$ & 2,291 & $1.7 \% \quad(39)$ & 2,330 & $1.6 \% \quad(38)$ & 0.04 & 0.850 \\
\hline Risperidone & $\geq 10 \mathrm{mg}$ & 1,478 & $1.7 \% \quad(25)$ & 1,564 & $0.8 \% \quad(13)$ & 4.56 & 0.033 \\
\hline Ziprasidone & $\geq 200 \mathrm{mg}$ & 272 & $8.1 \% \quad(22)$ & 343 & $5.8 \% \quad(20)$ & 1.21 & 0.270 \\
\hline $\begin{array}{l}\text { aThese are not counts of } \\
\text { antipsychotics during ea } \\
\text { bThe PA exemption peri } \\
\text { 'The post-PA exemption } \\
\text { dBecause a beneficiary } \\
\text { beneficiary counts for th } \\
\text { mg = milligrams; OVHA }\end{array}$ & $\begin{array}{l}\text { Ial PA requests, br } \\
\text { f the } 2 \text { study perio } \\
\text { as the 12-month } \\
\text { od was the 12-mo } \\
\text { have received mor } \\
\text { dividual drugs. } \\
\text { fice of Vermont H }\end{array}$ & $\begin{array}{l}\text { ounts of patients } \\
\text { the estimates ar } \\
\text { od from July } 1,2 \\
\text { period from Jan } \\
\text { han } 1 \text { atypical ar } \\
\text { h Access: } P A=p\end{array}$ & $\begin{array}{l}\text { ith daily doses above } \\
\text { hown at the the pati } \\
05 \text {, through June } 30 \text {, } \\
\text { ary 1, 2007, through } \\
\text { psychotic at high dos } \\
\text { authorization. }\end{array}$ & $\begin{array}{l}\text { he PA guidelines } \\
\text { t level. } \\
006 . \\
\text { ecember } 31,200 \\
\text { the total sample }\end{array}$ & $\begin{array}{l}\text { by the OVHA. }{ }^{14} \mathrm{Be} \\
\text { ze is the count of uni }\end{array}$ & $\begin{array}{l}\text { se patients cou } \\
\text { e beneficiaries, }\end{array}$ & $\begin{array}{l}\text { multiple } \\
\text { sum of the }\end{array}$ \\
\hline
\end{tabular}

2-tailed alpha level of 0.05, and all analyses were performed using SAS statistical software (Version 9.1.3, SAS Institute Inc., Cary, NC).

\section{Results}

The final study sample in the PA-exemption period (July 1, 2005, through June 30, 2006) was 124,169 (Figure 1). In the post-PA exemption period from January 1, 2007, through December 31, 2007, 123,449 beneficiaries met the criteria for study inclusion (Figure 2). The mean (SD) ages of Medicaid beneficiaries in this study were 20.4 (16.4) years in the PA exemption period and 21.2 (17.0) years in the post-PA exemption period (Table 2). The study population was predominantly younger than 18 years of age (54.9\% PA exemption period, $53.0 \%$ post-PA exemption period). Therefore, by definition, more than $50 \%$ of the population during the PA exemption period qualified for the SPMI exemption by age alone. The majority of beneficiaries were female $(53.8 \%$ of beneficiaries were female during both time periods). Race and ethnicity were also equally distributed in the 2 periods; however, a large portion of beneficiaries were missing race/ethnicity information during both study periods ( $>42 \%$ ).

The use of any behavioral health medication rose from $17.8 \%$ in the PA exemption period to $19.2 \%$ in the post-PA exemption period $(P<0.001$ ), a relative increase of $7.9 \%$ (Table 3). Utilization increased for each of the 3 sub-classes of behavioral health medications in the post-PA exemption period compared with the period in which the PA exemption was in effect, from $3.6 \%$ to $3.8 \%$ of beneficiaries who received antipsychotics $P=0.005$ ), from $14.4 \%$ to $15.4 \%$ of beneficiaries who received antidepressants $(P<0.001)$, and from $6.4 \%$ to $7.5 \%$ of beneficiaries who received anxiolytics/sedative hypnotics $(P<0.001)$.
There were 4,374 beneficiaries who received 1 or more atypical antipsychotics in the PA exemption period versus 4,586 beneficiaries in the post-PA exemption period (Table 4). The proportion of beneficiaries who received 1 or more highdose atypical antipsychotics that would have required a PA (for receipt of average daily dosing greater than the maximum established by OVHA) decreased from 3.1\% $(n=134)$ in the PA exemption period to $2.2 \%(n=101)$ in the period after discontinuation of the PA exemption $(P=0.011)$. Among the 6 individual atypical antipsychotics, the proportion of beneficiaries who should have received a PA for high-dose therapy declined significantly in the post-PA exemption period for aripiprazole, clozapine, and risperidone (Table 4).

Overall costs for pharmaceuticals increased from $\$ 82.5$ million in the 12-month period from July 1, 2005, through June 30,2006 , to $\$ 90.1$ million in the 12-month period from January 1, 2007, through December 31, 2007, or 9.9\% from $\$ 55.34$ to $\$ 60.82$ PMPM (Table 5). The costs for 3 classes of behavioral health medications increased by only $2.1 \%$ in the post-PA exemption period compared with the PA exemption period (from $\$ 12.76$ to $\$ 13.03$ PMPM), and therefore accounted for a smaller proportion of total pharmacy spending in the post-PA exemption period (21.4\%) compared with the PA exemption period (23.1\%).

The 9.9\% increase in PMPM spending for all drugs and the 2.1\% increase in PMPM spending for the 3 classes of behavioral health drugs were attributable to lower costs per pharmacy claim while utilization of behavioral health medications increased minimally. For all pharmaceuticals, the average cost per claim declined by $4.0 \%$ from $\$ 71.04$ to $\$ 68.21$ (Table 5). For the 3 classes of behavioral health drugs, the average cost per claim declined by $12.9 \%$, from $\$ 94.05$ to 
Cost and Utilization of Behavioral Health Medications Associated with Rescission of an Exemption for Prior Authorization for Severe and Persistent Mental Illness in the Vermont Medicaid Program

\section{TABLE 5 Utilization and CPI-Adjusted Medication Costs}

\begin{tabular}{|c|c|c|c|c|c|c|c|c|c|}
\hline & \multicolumn{2}{|c|}{$\begin{array}{l}\text { PA Exemption Cohort }{ }^{\mathrm{a}} \\
\mathrm{n}=124,169\end{array}$} & \multicolumn{2}{|c|}{$\begin{array}{l}\text { Post-PA Exemption Cohort }{ }^{b} \\
n=123,449\end{array}$} & \multicolumn{2}{|c|}{ Absolute Change } & \multirow{2}{*}{$\begin{array}{l}\text { Percent } \\
\text { Change } \\
(\%)^{\mathrm{c}}\end{array}$} & \multirow{2}{*}{$\begin{array}{c}\text { T-test } \\
\text { Statistic }\end{array}$} & \multirow[b]{2}{*}{$P$ Value } \\
\hline & Totale & PMPM & Totale & PMPM & Total & PMPM & & & \\
\hline \multicolumn{10}{|l|}{ All medications } \\
\hline Claims & $1,160,889$ & 0.78 & $1,320,875$ & 0.89 & 159,986 & 0.11 & 14.1 & \multirow{3}{*}{413.75} & \multirow{3}{*}{$<0.001$} \\
\hline Cost & $\$ 82,469,957$ & $\$ 55.34$ & $\$ 90,093,724$ & $\$ 60.82$ & $\$ 7,623,767$ & $\$ 5.48$ & 9.9 & & \\
\hline Cost per claim & $\$ 71.04$ & & $\$ 68.21$ & & $\$ 2.83$ & & -4.0 & & \\
\hline \multicolumn{10}{|c|}{ All nonbehavioral health medications } \\
\hline Claims & 958,666 & 0.64 & $1,085,334$ & 0.73 & 126,668 & 0.09 & 14.1 & \multirow{3}{*}{396.97} & \multirow{3}{*}{$<0.001$} \\
\hline Cost & $\$ 63,450,118$ & $\$ 42.58$ & $\$ 70,797,124$ & $\$ 47.79$ & $\$ 7,347,006$ & $\$ 5.21$ & 12.2 & & \\
\hline Cost per claim & $\$ 66.19$ & & $\$ 65.23$ & & $\$ 0.96$ & & -1.5 & & \\
\hline \multicolumn{10}{|c|}{ All behavioral health medications $\mathrm{f}$} \\
\hline Claims & 202,223 & 0.14 & 235,541 & 0.16 & 33,318 & 0.02 & 14.3 & \multirow{3}{*}{307.44} & \multirow{3}{*}{$<0.001$} \\
\hline Cost & $\$ 19,019,839$ & $\$ 12.76$ & $\$ 19,296,601$ & $\$ 13.03$ & $\$ 276,762$ & $\$ 0.27$ & 2.1 & & \\
\hline Cost per claim & $\$ 94.05$ & & $\$ 81.92$ & & $\$ 12.13$ & & -12.9 & & \\
\hline \multicolumn{10}{|l|}{ Antidepressants } \\
\hline Claims & 121,737 & 0.08 & 138,837 & 0.09 & 17,100 & 0.01 & 12.5 & \multirow{3}{*}{341.84} & \multirow{3}{*}{$<0.001$} \\
\hline Cost & $\$ 7,984,246$ & $\$ 5.36$ & $\$ 6,848,253$ & $\$ 4.62$ & $\$ 1,135,993$ & $\$ 0.74$ & -13.8 & & \\
\hline Cost per claim & $\$ 65.59$ & & $\$ 49.33$ & & $\$ 16.26$ & & -24.8 & & \\
\hline \multicolumn{10}{|l|}{ Antipsychotics } \\
\hline Claims & 41,972 & 0.03 & 48,371 & 0.03 & 6,399 & 0.00 & 0.0 & \multirow{3}{*}{215.21} & \multirow{3}{*}{$<0.001$} \\
\hline Cost & $\$ 9,886,726$ & $\$ 6.64$ & $\$ 10,936,675$ & $\$ 7.38$ & $\$ 1,049,949$ & $\$ 0.74$ & 11.1 & & \\
\hline Cost per claim & $\$ 235.56$ & & $\$ 226.10$ & & $\$ 9.46$ & & -4.0 & & \\
\hline \multicolumn{10}{|c|}{ Anxiolytics/sedative hypnotics } \\
\hline Claims & 38,514 & 0.03 & 48,333 & 0.03 & 9,819 & 0.00 & 0.0 & \multirow{3}{*}{134.02} & \multirow{3}{*}{$<0.001$} \\
\hline Cost & $\$ 1,148,867$ & $\$ 0.77$ & $\$ 1,511,673$ & $\$ 1.02$ & $\$ 362,806$ & $\$ 0.25$ & 32.5 & & \\
\hline Cost per claim & $\$ 29.83$ & & $\$ 31.28$ & & $\$ 1.45$ & & 4.9 & & \\
\hline
\end{tabular}

aThe PA exemption period was the 12 months between July 1, 2005, and June 30, 2006.

bThe post-PA exemption period was the 12 months between January 1, 2007, and December 31, 2007.

"For the "claims" and "costs" rows, represents the percentage change in the PMPM value. For the "cost per claim" rows, represents the percentage change in the cost per claim.

${ }^{d}$ Comparing the average PMPM cost in the 2 study cohorts.

'All costs were adjusted for inflation according to the December 2007 CPI for medical costs in the Boston-Brockton-Nashua area (489.80), which was the closest available geographical area to Vermont. Costs from all months (except December 2007) were inflated to more appropriately compare costs during a period of high inflation for medical costs. Claims are pharmacy claims.

fBehavioral health medications defined as antidepressants, antipsychotics, and anxiolytics/sedative hypnotics.

$C P I=$ Consumer Price Index; $P A=$ prior authorization; $P M P M=$ per member per month .

\$81.92. The antidepressants accounted for most of the drop in the average cost per claim for the behavioral health drugs, declining by $24.8 \%$ from $\$ 65.59$ to $\$ 49.33$; the average cost per claim for the antipsychotics declined by $4.0 \%$ from $\$ 235.56$ to $\$ 226.10$; while the average cost per claim for the anxiolytics/ sedative hypnotics increased by $4.9 \%$ from $\$ 29.83$ to $\$ 31.28$. The cost per claim for all nonbehavioral health drugs declined by $1.5 \%$ from $\$ 66.19$ to $\$ 65.23$.

The decline in the average cost per pharmacy claim helped suppress the effects of increased utilization in the post-PA exemption period for all drugs including the behavioral health drugs. Spending declined by $13.8 \%$ for antidepressants in the post-PA exemption period (from $\$ 5.36$ to $\$ 4.62 \mathrm{PMPM}$ ), but increased by $11.1 \%$ for antipsychotics (from $\$ 6.64$ to $\$ 7.38$ PMPM) and by $32.5 \%$ for the anxiolytics/sedative hypnotics (from $\$ 0.77$ to $\$ 1.02$ PMPM). Utilization of the 3 behavioral health classes of drugs was relatively stable at 0.14 claims PMPM in the PA exemption period and 0.16 claims PMPM in the post-PA exemption period, including essentially no change in the antidepressants, from 0.08 claims PMPM to 0.09 claims PMPM, and no change in the antipsychotics and the anxiolytics/sedative hypnotics, both 0.03 claims PMPM in both study periods (Table 5).

Regardless of study period, antipsychotics accounted for the largest proportion of spending on the 3 classes of behavioral medications, followed by antidepressants. In the PA exemption period, antipsychotics accounted for $12.0 \%$ of total pharmacy costs $(\$ 9,866,726$ of $\$ 82,469,957)$ and antidepressants for $9.7 \%$ of total pharmacy costs $(\$ 7,984,246$ of $\$ 82,469,957)$. A similar percentage of overall pharmaceutical expenditures were accounted for by these medication classes in the post-PA exemption period. After the PA exemption phase- 
Cost and Utilization of Behavioral Health Medications Associated with Rescission of an Exemption for Prior Authorization for Severe and Persistent Mental Illness in the Vermont Medicaid Program

TABLE 6 Incidence of Mental Health Inpatient Hospitalization by Subtype Stratified by Study Period

\begin{tabular}{|c|c|c|c|c|c|c|c|c|}
\hline & \multicolumn{2}{|c|}{$\begin{array}{c}\text { PA Exemption Cohort } \\
n=124,169\end{array}$} & \multicolumn{2}{|c|}{$\begin{array}{l}\text { Post-PA Exemption Cohort }{ }^{\mathrm{b}} \\
\mathrm{n}=123,449\end{array}$} & \multirow[b]{2}{*}{$\begin{array}{l}\text { Absolute } \\
\text { Change }^{c}\end{array}$} & \multirow[b]{2}{*}{$\begin{array}{c}\text { Percent } \\
\text { Change } \\
(\%)^{\mathrm{c}}\end{array}$} & \multirow[b]{2}{*}{$\begin{array}{l}\text { Pearson } \\
\text { Chi- } \\
\text { Square }^{\mathrm{c}}\end{array}$} & \multirow[b]{2}{*}{$P$ Value $^{\mathrm{c}}$} \\
\hline & $\begin{array}{l}\text { Total Number of } \\
\text { Hospitalizations }\end{array}$ & $\begin{array}{c}\text { Percent of } \\
\text { Beneficiaries } \\
\text { with at Least } 1 \\
\text { Hospitalization (n) }\end{array}$ & $\begin{array}{l}\text { Total Number of } \\
\text { Hospitalizations }\end{array}$ & \begin{tabular}{|c} 
Percent of \\
Beneficiaries \\
with at Least 1 \\
Hospitalization (n)
\end{tabular} & & & & \\
\hline $\begin{array}{l}\text { Any mental health } \\
\text { hospitalizationd }^{\mathrm{d}}\end{array}$ & 1,099 & $0.64 \%(799)$ & 608 & $0.37 \% \quad(461)$ & 0.27 & -42.2 & 89.17 & $<0.001$ \\
\hline Depression & 459 & $0.29 \% \quad(359)$ & 221 & $0.15 \% \quad(181)$ & 0.14 & -48.3 & 57.77 & $<0.001$ \\
\hline Schizophrenia & 99 & $0.05 \% \quad(65)$ & 60 & $0.04 \% \quad(44)$ & 0.01 & -20.0 & 3.93 & 0.048 \\
\hline Bipolar disorder & 155 & $0.11 \% \quad(137)$ & 95 & $0.06 \% \quad(78)$ & 0.05 & -45.5 & 15.86 & $<0.001$ \\
\hline Personality disorder & 23 & $0.01 \% \quad(18)$ & 20 & $0.01 \% \quad(15)$ & 0.00 & 0.0 & 0.26 & 0.613 \\
\hline Anxiety disorder & 151 & $0.10 \% \quad(120)$ & 98 & $0.07 \% \quad(81)$ & 0.03 & -30.0 & 7.35 & 0.007 \\
\hline Other disorders ${ }^{\mathrm{e}}$ & 212 & $0.15 \% \quad(185)$ & 114 & $0.08 \% \quad(99)$ & 0.07 & -46.7 & 25.57 & $<0.001$ \\
\hline $\begin{array}{l}\text { aThe PA-exemption per } \\
{ }^{b} \text { The post-PA exemptior } \\
{ }^{c} \text { Calculated by compari } \\
{ }^{d} \text { Total number of benef } \\
\text { other disorder. } \\
\text { 'Other mental health d } \\
\text { ICD-9-CM = Internatio }\end{array}$ & $\begin{array}{l}\text { was the } 12 \text { months be } \\
\text { riod was the } 12 \text { mont } \\
\text { the percentage of bene } \\
\text { ries who had at least } \\
\text { ders are specified by } t \\
\text { Classification of Dise }\end{array}$ & $\begin{array}{l}\text { etween July } 1,2005 \text {, and } \\
\text { ths between January } 1,2 \\
\text { eficiaries with at least } 1 \\
1 \text { mental health hospital } \\
\text { the ICD-9-CM codes in } \\
\text { eases, Ninth Revision, C }\end{array}$ & $\begin{array}{l}\text { June 30, } 2006 \text {. } \\
007 \text {, and December } 3 \\
\text { hospitalization in each } \\
\text { zation for depression, } \\
\text { Table } 1 .\end{array}$ & $\begin{array}{l}1,2007 . \\
\text { h study period. } \\
\text { schizophrenia, bipolar d } \\
\text { A = prior authorization }\end{array}$ & order, $p$ & ality di. & anxie & rder, or \\
\hline
\end{tabular}

out, the cost of antipsychotics increased by approximately $\$ 1,050,000$, and the cost of anxiolytics/sedatives increased in this time period by approximately $\$ 363,000$. However, during this time period, the cost of antidepressants decreased by approximately $\$ 1,136,000$. Spending on all medications other than behavioral health medications rose by approximately $\$ 7.35$ million, and total pharmaceutical spending rose by approximately $\$ 7.62$ million (9.2\%) in the post-PA exemption period compared with the PA exemption period.

Results of the analyses of inpatient hospitalizations attributable to behavioral health disorders are presented in Table 6. Overall, during the PA-exemption period, there were 491 (44.7\%) fewer mental health inpatient hospitalizations in the post-PA exemption period $(n=608)$ compared with the PA exemption period $(n=1,099)$. The unique count of beneficiaries with any mental health hospitalization (at least 1 hospitalization for depression, schizophrenia, bipolar disorder, personality disorder, or other mental health disorders) decreased from $0.64 \%(n=799)$ to $0.37 \%(n=461 ; P<0.001)$. The rates of hospitalization for 5 of the 6 specific mental health diagnostic categories were significantly lower in the period after removal of the PA exemption compared with the period of the PA exemption (Table 6).

\section{Discussion}

We conducted a retrospective cohort study to quantify the effect of a managed care initiative to promote the costeffective utilization of behavioral health medications and services. Rather than directly evaluating the effect of program implementation, we focused on the phase-out of an exemption that allowed certain beneficiaries with "severe and persistent mental illness" to be exempt from the initiative. All covered beneficiaries in the state of Vermont were subject to the use of a PDL after the SPMI exemption was phased out in June 2006, and thus if the implementation of the PDL was effective, changes in utilization and costs should be evident following the phase-out of the exemption. Our study is important because evaluation of public programs is imperative to ensure that health care initiatives maintain quality while being costeffective and use available resources efficiently.

Since a large portion of the population qualified for exemption from the implementation of the PDL, it is not surprising that costs for behavioral health medications continued to escalate after implementation of the PDL. However, our analysis shows only a modest 2\% increase in PMPM costs for behavioral health medications, while PMPM costs increased $12 \%$ for all other pharmaceuticals following the phase-out of the PA exemption. This suggests that the implementation of a PDL with a corresponding PA process may be an effective tool for managing cost increases without adversely affecting utilization of target drugs in a publicly funded pharmaceutical assistance program. Equally important was the relatively stable utilization of behavioral health medications between the 2 time periods, indicating that the implementation of the PDL may be shifting prescribing towards more cost-effective medications while not deterring medication prescribing as warranted for mental health conditions.

Our analyses also indicated that hospitalizations and high-dose prescriptions of antipsychotic medications did not increase in the period after elimination of the PA exemption for 


\section{Cost and Utilization of Behavioral Health Medications Associated with Rescission of an Exemption for Prior Authorization for Severe and Persistent Mental Illness in the Vermont Medicaid Program}

mental health drugs. Hospitalizations decreased by almost onehalf in the year after elimination of the exemption (2007). More research may help determine if treatment was shifted to other areas, such as outpatient clinics, and to our knowledge there were no other initiatives by OVHA targeting mental health inpatient hospitalizations. Research by Shern et al. (2008) suggested that mental health costs shifted from health care centers to private care through family and friends after the introduction of Medicaid managed care. ${ }^{16}$ In that study, although costs to the Florida Medicaid system did decrease in the presence of managed care, there were no differences in societal costs. It is plausible that the decrease in inpatient hospitalizations seen in this study resulted in subsequent increases in care in other health care sectors.

Kaskie et al. (2006) compared 2 capitated models of Medicaid mental health service delivery with traditional feefor-service Medicaid among enrollees aged 65 years or older in Colorado. ${ }^{17}$ Although our study population differed by the exclusion of Medicare-eligible enrollees, Kaskie et al. also found that the introduction of behavioral health managed care to a Medicaid population reduced expenditures while having mixed results on rates of utilization. Authors of several studies have noted that introduction of behavioral health managed care was associated with reduced utilization of inpatient care..$^{18-20}$ However, Burns et al. (1999) noted that utilization of intensive outpatient services increased, while Cook et al. (2004) did not observe any change in outpatient service utilization. ${ }^{18,20} \mathrm{~A}$ multisite study by Leff et al. (2005) concluded that enrolling highuse Medicaid beneficiaries in behavioral health managed care programs (e.g., behavioral health "carve-outs") did not seem to pose any short-term, large-scale negative consequences, such as an increase in the utilization of intensive inpatient mental health services. ${ }^{21}$

Research by Soumerai et al. indicated that managed care restrictions could have a negative impact on Medicaid subpopulations..$^{22-26}$ A much-referenced study by Soumerai et al. (1994) found reductions in the use of behavioral health medications and increased use of mental health services following the implementation of a 3-prescription monthly payment limit on psychotropic drugs and acute mental health care in noninstitutionalized beneficiaries with acute schizophrenia. ${ }^{23}$ A more recent (2008) analysis concluded that the initiation of PA for nonpreferred antipsychotics in West Virginia and Texas decreased the market share of these agents by $13.9 \%$ and $2.6 \%$ respectively after 2 years but was not associated with significant reduction in pharmacy reimbursements in either state. ${ }^{24}$ The authors noted that the economic value of supplemental rebates associated with the PDL and not reported in available pharmacy claims could not be evaluated.

\section{Limitations}

Foremost among the limitations of this study, we did not include a comparison group from another state, but rather used a pre and post design. As a result, we cannot differentiate the effect of extraneous changes in the marketplace from the effect of rescission of the PA exemption for SPMI. However, apparent differences between the population covered in the state of Vermont's Medicaid program and other state Medicaid programs would make selection of a valid comparison group problematic even if one were available.

Second, our study is a real-world analysis of a managed care policy change, and we do not know the proportion of the study cohorts that was affected by the PA exemption. We do know that the proportion affected by the exemption was greater than $50 \%$ of the cohort samples by age alone.

Third, our analyses were restricted to the costs paid to pharmacies by the OVHA as recorded in pharmacy claims databases. We were unable to account for manufacturer rebates that have been negotiated by OVHA, and thus the true costs to the Medicaid program may be overstated. In addition to federal rebates, Vermont participates in a multistate pool for supplemental rebates with Michigan, Alaska, Nevada, New Hampshire, Hawaii, and Minnesota. ${ }^{12}$ Drug manufacturer rebates are significant in Medicaid pharmacy programs, ${ }^{27}$ but we have no reason to believe that rebate revenues as a proportion of total spending for mental health drugs would have differed between the 2 time periods in the present study. Although not broken out by drug class, the state of Vermont reported that federal rebates were about $27.1 \%$ of total pharmacy spending in the state's fiscal year 2008, plus an additional $4.7 \%$ in supplemental rebates. ${ }^{28}$

Fourth, we are unable to ascertain the effect of "grandfathering" on costs and utilization. Prior to rescission of the PA exemption, behavioral health medication users were grandfathered to prevent "destabilization." ${ }^{14}$ New users and beneficiaries who had lapses in treatment greater than 4 months became subject to the PDL upon implementation of the rescission. ${ }^{14}$ Our study was designed to mitigate the effects of grandfathered users of behavioral health medications by employing a 6-month "wash-out" period. Published data indicate that Vermont Medicaid PAs for nonpreferred behavioral health medications decreased by approximately 54\% from January 2006 to November 2007..14 This decrease may have resulted from greater adherence to the PDL, although an analysis of this association is beyond the scope of the present study.

Fifth, because we did not have a comparison group from another state, we could not ascertain the effects of increased awareness and attention to the relationship between antipsychotic use and a higher prevalence of other disorders such as metabolic syndrome. ${ }^{29-31}$ This syndrome is often 


\section{Cost and Utilization of Behavioral Health Medications Associated with Rescission of an Exemption for Prior Authorization for Severe and Persistent Mental Illness in the Vermont Medicaid Program}

characterized by obesity, hypertension, dyslipidemia, hyperuricemia, and diabetes, ${ }^{29}$ and people with this constellation of risk factors have a higher risk for cardiovascular and/or all-cause mortality. ${ }^{31}$ Therefore, patients taking antipsychotic medications might have higher overall drug costs than the rest of the Medicaid population due to this association. In fact, a cross-sectional observational study of adult Medicaid beneficiaries found that the presence of any psychiatric diagnosis significantly increased total health care costs by over 200\% $\left(\$ 3,121\right.$ per year to $\$ 6,995$ per year). ${ }^{32}$ Heightened awareness of the metabolic syndrome may have led to a reduction in the use of these medications independent of the phase-out of the SPMI exemption. Recent research has added further confirmation of this association. ${ }^{32}$

Sixth, we did not explore the reasons for the reduction in average drug cost per pharmacy claim for the 3 mental health drug classes combined, and for the antidepressants in particular, in the period after elimination of the PA exemption. One obvious reason is greater adherence to the PDL including the use of more first-line therapy including generic antidepressants such as citalopram, paroxetine, and sertraline (which first became available by generic name in June 2006).

\section{Conclusion}

Many states such as Vermont have introduced managed care initiatives in their publicly funded health care programs in an attempt to maintain quality and restrain cost increases. The exemption of behavioral health medications from PA for Medicaid beneficiaries with SPMI was implemented in Vermont in response to criticism about the possible adverse effects on a "vulnerable" population. Phase-out of the PA exemption was completed in June 2006, but current users of behavioral health medications continued to be "grandfathered" until a lapse in drug therapy of 4 months or longer occurred. Therefore, the phase-out of the PA exemption provided an opportunity to analyze the effect of behavioral health managed care in this Medicaid population. The growth of PMPM cost for behavioral health medications, which represented $21 \%-23 \%$ of total pharmaceutical costs, was small compared with the increase in PMPM costs for nonbehavioral health medications. Secondary analyses of 2 quality measures, the percentage of beneficiaries who were hospitalized with mental health diagnoses and highdose prescribing of antipsychotics, declined after removal of the PA exemption. Despite the PA requirement, utilization of behavioral health medications PMPM remained stable, and there was a decrease in the average prescription cost for the behavioral health medications, particularly antidepressants.

\section{Authors}

JASON C. SIMEONE, PhD, is a postdoctoral fellow in the Program in Pharmacoepidemiology and Pharmacoeconomics, College of Pharmacy, University of Rhode Island, Kingston, Rhode Island; RITA M. MARCOUX, MBA, RPh, is an Assistant Research Professor, College of Pharmacy, University of Rhode Island, Kingston, Rhode Island; and BRIAN J. QUILLIAM, PhD, RPh, is Associate Professor of Pharmacoepidemiology, College of Pharmacy, University of Rhode Island, Kingston, Rhode Island.

AUTHOR CORRESPONDENCE: Jason C. Simeone, PhD, College of Pharmacy, University of Rhode Island, 41 Lower College Road, Kingston, RI 02881. Tel.: 401.874.2035; Fax: 401.874.2035;

E-mail: jasoncsimeone@mail.uri.edu.

\section{DISCLOSURES}

This research was conducted in a university setting without external funding. Simeone designed the study with the assistance of Quilliam. Marcoux collected the data, and the 3 authors shared in data interpretation. Simeone wrote and revised the manuscript with the assistance of Marcoux and Quilliam.

\section{ACKNOWLEDGEMENTS}

The authors thank Ann E. Rugg, former Deputy Director of the Office of Vermont Health Access (OVHA) for her assistance in obtaining data from OVHA used in these analyses and for her insight on the policies evaluated in this project.

\section{REFERENCES}

1. Smith VK, Gifford K, Ellis E, Rudowitz R, Watts MO, Marks C. The crunch continues: Medicaid spending, coverage, and policy in the midst of a recession. Results from a 50-state Medicaid budget survey for state fiscal years 2009 and 2010. Kaiser Commission on Medicaid and the uninsured. September 2009. Available at: http://www.kff.org/medicaid/upload/7985. pdf. Accessed May 5, 2010.

2. Holahan J, Yemane A. Enrollment is driving Medicaid costs- but two targets can yield savings. Health Aff (Millwood). 2009;28(5):1453-65.

3. Kimbuende E, Ranji E, Salganicoff A. Prescription drug costs: background brief. Kaiser Family Foundation. February 2010. Available at: http://www. kaiseredu.org/topics_im.asp?id=352\&parentID=68\&imID=1. Accessed May $5,2010$.

4. U.S. Department of Health and Human Services, Centers for Medicare \& Medicaid Services. National summary of Medicaid managed care programs and enrollment as of June 30, 2008. Available at: http://www.cms.hhs.gov/ MedicaidDataSourcesGenInfo/downloads/08Trends508.pdf. Accessed May 11,2010

5. Congress of the United States, Congressional Budget Office. Medicaid's reimbursements to pharmacies for prescription drugs. December 2004. Available at: http://www.cbo.gov/ftpdocs/60xx/doc6038/12-16-Medicaid.pdf. Accessed May 11, 2010.

6. Mechanic D. Managed mental health care. Society. 1997;35(1):44-52.

7. Office of the Inspector General, Department of Health and Human Services. Medicaid's mental health drug expenditures. August 2003.

Available at: http://oig.hhs.gov/oei/reports/oei-05-02-00080.pdf. Accessed May 11, 2010. 


\section{Cost and Utilization of Behavioral Health Medications Associated with Rescission of an Exemption for Prior Authorization for Severe and Persistent Mental Illness in the Vermont Medicaid Program}

8. Walton SM, Schumock GT, Lee KV, Alexander GC, Meltzer D, Stafford RS. Prioritizing future research on off-label prescribing: results of a quantitative evaluation. Pharmacotherapy. 2008;28(12):1443-52.

9. Pharmaceutical and Research Manufacturers of America. Pharmaceutical research companies are developing more than 300 medicines to treat mental illnesses. Available at: http://www.phrma.org/files/attachments/Mental\%20 Illness\%202008.pdf. Accessed April 27, 2010.

10. Dean H. Vermont State of the State Address 2000. January 5, 2000 Available at: http://www.stateline.org/live/details/speech?contentId=16008. Accessed November 20, 2009

11. General Assembly of the State of Vermont. An act relating to prescription drug cost containment and affordable access. Legislation No. $127 \mathrm{Sec} .1$. 33 V.S.A. chapter 19, subchapter 5. Available at: http://www.leg.state.vt.us/ DOCS/2002/ACTS/ACT127.HTM. Accessed November 13, 2009.

12. State of Vermont Joint Fiscal Office. Evaluation of savings attributable to Medicaid pharmaceutical cost containment. February 2003. Available at: http://www.leg.state.vt.us/JFO/Healthcare/Pharmaceutical\%20Savings.pdf. Accessed November 13, 2009.

13. Mulligan K. Vermont gives formulary exemption to psychiatric drugs. Psych News, 2002;37(16):4. Available at: http://pn.psychiatryonline.org/content/37/16/4.full. Accessed May 12, 2010.

14. Office of Vermont Health Access, Agency of Human Services. Report: health access oversight committee, pharmacy benefit management program, behavioral health drug management plan. September 2005. Available at: http://ovha.vermont.gov/budget-legislative/haocreport090105.pdf. Accessed May 11, 2010

15. Perrins G, Nilsen D. Math calculations to better utilize CPI data. Bureau of Labor Statistics. Available at: http://www.bls.gov/cpi/cpimathfs.pdf. Accessed May 5, 2010.

16. Shern DL, Jones K, Chen HJ, Jordan N, Ramoni-Perazzi J, Boothroyd RA. Medicaid managed care and the distribution of societal costs for persons with severe mental illness. Am J Psychiatry. 2008;165(2):254-60. Available at: http://ajp.psychiatryonline.org/cgi/reprint/165/2/254. Accessed April 28, 2010.

17. Kaskie B, Wallace N, Kang S, Bloom J. The implementation of managed behavioral healthcare in Colorado and the effects on older Medicaid beneficiaries. J Ment Health Policy Econ. 2006;9(1):15-24.

18. Burns BJ, Teagle SE, Schwartz M, Angold A, Holtzman A. Managed behavioral health care: a Medicaid carve-out for youth. Health Aff (Millwood) 1999;18(5):214-25. Available at: http://content.healthaffairs.org/cgi/ reprint/18/5/214.pdf. Accessed May 13, 2010.

19. Raghavan R, Leibowitz AA, Andersen RM, Zima BT, Schuster MA, Landsverk J. Effects of Medicaid managed care policies on mental health service use among a national probability sample of children in the child welfare system. Child Youth Serv Rev. 2006;28(12):1482-96.

20. Cook JA, Heflinger CA, Hoven CW, et al. A multi-site study of Medicaidfunded managed care versus fee-for-service plans' effects on mental health service utilization of children with severe emotional disturbance. J Behav Health Serv Res. 2004;31(4);384-402.
21. Leff HS, Wieman DA, McFarland BH, et al. Assessment of Medicaid managed behavioral health care for persons with serious mental illness Psychiatr Serv. 2005;56(10):1245-53. Available at: http://ps.psychiatryonline. org/cgi/reprint/56/10/1245. Accessed March 21, 2010.

22. Soumerai SB, Ross-Degnan D, Avorn J, McLaughlin T, Choodnovskiy I. Effects of Medicaid drug-payment limits on admissions to hospitals and nursing homes. N Engl J Med. 1991;325(15):1072-77.

23. Soumerai SB, McLaughlin TJ, Ross-Degnan D, Casteris CS, Bollini P. Effects of a limit on Medicaid drug-reimbursement benefits on the use of psychotropic agents and acute mental health services by patients with schizophrenia. N Engl J Med. 1994;331(10):650-55. Available at: http://content.nejm.org/cgi/content/full/331/10/650. Accessed March 20, 2010.

24. Law MR, Ross-Degnan D, Soumerai SB. Effects of prior authorization of second-generation antipsychotic agents on pharmacy utilization and reimbursements. Psychiatr Serv. 2008;59(5):540-46. Available at: http:// ps.psychiatryonline.org/cgi/reprint/59/5/540. Accessed March 21, 2010.

25. Soumerai SB, Zhang F, Ross-Degnan D, et al. Use of atypical antipsychotic drugs for schizophrenia in Maine Medicaid following a policy change. Health Aff (Millwood). 2008;27(3):185-95.

26. Zhang Y, Adams AS, Ross-Degnan D, Zhang F, Soumerai SB. Effects of prior authorization on medication discontinuation among Medicaid beneficiaries with bipolar disorder. Psychiatr Serv. 2009;60(4):520-27. Available at: http://ps.psychiatryonline.org/cgi/reprint/60/4/520. Accessed April 28, 2010

27. Fischer MA, Avorn J. Economic consequences of underuse of generic drugs: evidence from Medicaid and implications for prescription drug benefit plans. Health Serv Res. 2003;38(4):1051-63. Available at: http://www. ncbi.nlm.nih.gov/pmc/articles/PMC1360932/pdf/hesr_162.pdf. Accessed May 13, 2010.

28. Office of Vermont Health Access, Agency of Human Services. Pharmacy best practices and cost control report 2009. Available at: http://ovha. vermont.gov/for-providers/pharmacy-best-practices-and-cost-controlreport-2009.pdf. Accessed May 11, 2010.

29. Lieberman JA 3rd. Metabolic changes associated with antipsychotic use. Prim Care Companion J Clin Psychiatry. 2004:6(Suppl 2):8-13. Available at: http://www.ncbi.nlm.nih.gov/pmc/articles/PMC487012/pdf/i1523-59986-s2-8.pdf. Accessed April 28, 2010

30. Toalson P, Ahmed S, Hardy T, Kabinoff G. The metabolic syndrome in patients with severe mental illnesses. Prim Care Companion J Clin Psychiatry. 2004;6(4):152-58. Available at: http://www.ncbi.nlm.nih.gov/pmc/articles/ PMC514841/pdf/i1523-5998-6-4-152.pdf. Accessed April 28, 2010.

31. Mackin P, Bishop DR, Watkinson HM. A prospective study of monitoring practices for metabolic disease in antipsychotic-treated community psychiatric patients. BMC Psychiatry. 2007;7(28). Available at: http://www.ncbi.nlm. nih.gov/pmc/articles/PMC1913512/pdf/1471-244X-7-28.pdf. Accessed March 20, 2010.

32. Thomas MR, Waxmonsky JA, Gabow PA, Flanders-McGinnis G, Socherman R, Rost K. Prevalence of psychiatric disorders and costs of care among adult enrollees in a Medicaid HMO. Psychiatr Serv. 2005;56(11):1394401. Available at: http://ps.psychiatryonline.org/cgi/reprint/56/11/1394 Accessed April 28, 2010. 